Bloot, L., Heins, M.J., Donders, R., Bleijenberg, G., Knoop, H. The process of change in pain during cognitive-behavior therapy for chronic fatigue syndrome. Clinical Journal of Pain: 2015, 31(10), 914-921

\begin{tabular}{|c|c|}
\hline $\begin{array}{l}\text { Postprint } \\
\text { Version }\end{array}$ & 1.0 \\
\hline Journal website & $\begin{array}{l}\text { http://pt.wkhealth.com/pt/re/lwwgateway/landingpage.htm;jsessionid=XNTckMyV } \\
\text { pSZKWJF4JmsvGvJBVvTXXXQTD8VyspT6y15G|3PDJnQc!- } \\
\underline{\text { 651508617!181195628!8091!-1?sid=WKPTLP:landingpage\&an=00002508- }} \\
\underline{201510000-00010}\end{array}$ \\
\hline Pubmed link & http://www.ncbi.nlm.nih.gov/pubmed/25503595 \\
\hline DOI & 10.1097/AJP.0000000000000191 \\
\hline
\end{tabular}

This is a NIVEL certified Post Print, more info at http://www.nivel.eu

\title{
The Process of Change in Pain During Cognitive- Behavior Therapy for Chronic Fatigue Syndrome
}

\author{
Lotte Bloot, MSc, ${ }^{*}$ Marianne J. Heins, PhD, ${ }^{*}$ Rogier Donders, PhD, w Gijs \\ BleiJenBERG, PHD, ${ }^{*}$ AND HANS KNOOP, PHD*
}

\begin{abstract}
Background: Cognitive-behavior therapy (CBT) leads to a reduction of fatigue and pain in chronic fatigue syndrome. The processes underlying the reduction in pain have not been investigated.

Recently, it was shown that increased self-efficacy, decreased focusing on symptoms, increased physical functioning, and a change in beliefs about activity contribute to the decrease in fatigue.

Objectives: The present study has 2 objectives: (1) to determine the relationship between the reduction of fatigue and pain during CBT; (2) test to what extent the model for change in fatigue is applicable to the reduction in pain.

Materials and Methods: One hundred forty-two patients meeting United States centers for Disease Control and Prevention criteria for chronic fatigue syndrome, currently reporting pain, and starting CBT were included. A crosslagged analysis was performed to study the causal direction of change between pain and fatigue. Pain and process variables were assessed before therapy, 3 times during CBT, and after therapy. Actual physical activity was also assessed. The model was tested with multiple regression analyses.

Results: The direction of change between pain and fatigue could not be determined. An increase in physical functioning and decrease in focusing on symptoms explained $4 \%$ to $14 \%$ of the change in pain.

Conclusions: Pain and fatigue most probably decrease simultaneously during CBT. Pain reduction can partly be explained by a reduction of symptom focusing and increased physical functioning.

Additional, yet unknown cognitive-behavioral factors also play a role in the reduction of pain.
\end{abstract}

Chronic fatigue syndrome (CFS) is a condition estimated to affect about $0.18 \%$ to $0.5 \%$ of the population. ${ }^{1}$ To meet the widely used United States Centers for Disease Control and Prevention criteria of CFS, a patient has to be severely fatigued and the fatigue has to lead to impairments in daily functioning. The fatigue has to last at least 
Bloot, L., Heins, M.J., Donders, R., Bleijenberg, G., Knoop, H. The process of change in pain during cognitive-behavior therapy for chronic fatigue syndrome. Clinical Journal of Pain: 2015, 31(10), 914-921

6 months and a somatic cause must be excluded. In addition, a patient must report at least 4 of the following 8 symptoms: unrefreshing sleep, forgetfulness or concentration problems, sore throat, joint pain, muscle pain, headaches, tender lymph nodes, or postexertional malaise. ${ }^{2,3}$ Four of these accompanying symptoms are pain symptoms. Pain in CFS is common: the majority of patients report chronic widespread pain and headaches. ${ }^{4,5}$ Chronic pain symptoms account for up to a third of the impairments in daily functioning reported by CFS patients. ${ }^{6,7}$ Cognitivebehavior therapy (CBT) is an effective treatment for CFS, which can reduce fatigue and disabilities.

${ }^{8-10}$ CBT for CFS is aimed at changing the perpetuating factors of fatigue, and involves the challenging of fatigue-related dysfunctional beliefs and a gradual increase of activity. ${ }^{11,12}$ According to the model of Vercoulen et al ${ }^{13,14}$ perpetuating factors in CFS are focusing on bodily symptoms, low self-efficacy with regard to symptoms, a low level of activity, a perceived lack of social support or (over) acknowledgment of the symptoms, which maintain in functional impairment and fatigue. ${ }^{1,11}$ Knoop et $\mathrm{al}^{4}$ found that CBT for CFS also leads to a decrease in pain. Compared with patients without a clinically significant reduction of fatigue, patients with a clinically significant reduction of fatigue more often had pain levels comparable with healthy controls after treatment.

Also, the number of pain locations had decreased following a clinically significant reduction of fatigue. A relationship was found between the decrease in pain and fatigue. The nature of this relationship is unknown: does a decrease in fatigue lead to a decrease in pain or does a decrease in pain lead to a decrease in fatigue? Or more likely, does CBT lead to changes in processes that lead to both a reduction in fatigue and pain? The direction of change between fatigue and pain has not yet been studied in CFS.

The model of perpetuating factors used in CBT for CFS may explain why patients remain fatigued, but it does not necessarily explain the mechanism of change that leads to a reduction in fatigue during therapy. To examine the mechanism of change occurring during treatment, mediation analysis can be used. It attempts to identify variables that possibly contribute to the relationship between treatment and outcome. ${ }^{15}$ Wiborg et $\mathrm{al}^{16}$ investigated which changes in cognitions and behaviors were responsible for the reduction in fatigue and disabilities after CBT for CFS. In the treatment model they developed, the decrease in fatigue was explained by an increase in sense of control over fatigue (self-efficacy), an increased level of (selfreported) activity, and an improved physical functioning. A limitation to the model of Wiborg et $\mathrm{al}^{16}$ was that variables were only measured before and after therapy, which means that the process of change during therapy was not analyzed. Heins et $\mathrm{al}^{17}$ studied the process of change during CBT for CFS, by measuring both fatigue and the change in cognitions and behavior several times during therapy. They partly replicated the findings of Wiborg et al. ${ }^{16}$ An increase in self-efficacy, selfreported physical activity, and physical functioning was related to the reduction of fatigue. Furthermore, the investigators found that a decrease in focusing on symptoms is related to a decrease in fatigue. In both studies an increase in actual physical activity was not related to a decrease in fatigue.

It is conceivable that the same processes that are responsible for the reduction of fatigue also underlie the reduction of pain during CBT for CFS. Recently, Nijs et al ${ }^{18}$ reviewed the evidence for pain in CFS as a unique characteristic versus the 
Bloot, L., Heins, M.J., Donders, R., Bleijenberg, G., Knoop, H. The process of change in pain during cognitive-behavior therapy for chronic fatigue syndrome. Clinical Journal of Pain: 2015, 31(10), 914-921

expression of an underlying pathophysiological process that is similar to fatigue. They assume that pain in CFS is caused by both an increased peripheral sensitivity to pain stimuli and central sensitization. The latter not only for pain but also for other bodily signals, like fatigue. This would explain the relationship found between the decrease in pain and decrease in fatigue. ${ }^{4}$ Nijs et al ${ }^{18}$ also discuss that in these central processes several psychological factors, like catastrophizing cognitions, depression, maladaptive illness perceptions, and maladaptive pain cognitions are involved. There is substantial overlap between these psychological factors and the mediators of the change in fatigue found by Wiborg et al ${ }^{16}$ and Heins et al. ${ }^{17}$ Especially the increased self-efficacy, reduced focusing on bodily symptoms, and increased perceived activity are very similar to the cognitive processes thought to play a role in central sensitization. If there is a central mechanism of sensitization in CFS that leads to an increased perception of both pain and fatigue, it would be expected that the changes in aforementioned cognitive processes responsible for the reduction in fatigue would also (partially) account for the reduction in pain.

The hypothesized overlap has thus far not been empirically tested. The main aim of the present study was to investigate the process of change in pain during CBT for CFS. First objective of this study was to examine the direction of change between fatigue and pain. As CBT for CFS is aimed at reducing fatigue, it could be expected that fatigue decreases before pain decreases. It seems unlikely that the decrease of pain precedes that of fatigue, but this cannot be ruled out on the basis of current data. If central sensitization is responsible for the increased perception of both fatigue and pain, one would expect that the effects of CBT on the cognitive processes that are involved in central sensitization would lead to a simultaneous decrease of fatigue and pain. That is why the second objective of this study was to test to what extent the change in cognitive processes that brings on the reduction in fatigue in CBT for CFS, that is an increased self-efficacy, increased perceived activity, and reduced focusing on symptoms, were also responsible for the reduction of pain. Therefore, we tested if the treatment model for fatigue reported by Heins et $\mathrm{al}^{17}$ could also explain the reduction in pain severity during CBT for CFS. Heins and colleagues measured the selfefficacy with respect to fatigue, but self-efficacy is not limited to fatigue and likely to be associated with the selfefficacy with respect to other CFS symptoms. They also found that a decrease in focusing on bodily symptoms was related to a decrease in fatigue. Focusing on bodily symptoms is not limited to fatigue as well and can also be extended to pain. Both Wiborg and colleagues and Heins and colleagues found that an increase in physical functioning is also related to the reduction in fatigue. Although this variable is not related to the model of central sensitization, as it is part of the treatment model of CBT for CFS, we also tested its role in the change in pain.

Knoop et $\mathrm{al}^{4}$ found that the change in actual physical activity during therapy measured pretreatment and posttreatment, was not a predictor for the change in pain in CFS patients. Actual physical activity was measured with an actigraph, a device worn around the ankle that senses motion. Heins et $\mathrm{al}^{17}$ found that, although actual physical activity during therapy temporarily increased, this increase was not related to a reduction in fatigue. However, in a comparable condition, that is fibromyalgia (characterized by widespread pain), increased objective physical activity has been linked to a decrease in pain. ${ }^{19,20}$ In other chronic pain syndromes like lower back pain, ${ }^{21}$ physical exercise has also been proven to reduce pain symptoms. It has been 
Bloot, L., Heins, M.J., Donders, R., Bleijenberg, G., Knoop, H. The process of change in pain during cognitive-behavior therapy for chronic fatigue syndrome. Clinical Journal of Pain: 2015, 31(10), 914-921

suggested that in healthy persons exercise leads to an increase in pain thresholds by releasing endogenous opioids. ${ }^{22}$ Also the brain activates (supra) spinal nociceptive inhibitory mechanisms. ${ }^{23}$ Both these mechanisms would lead to a reduction in pain. In the light of these research findings one would expect an increase in actual physical activity during CBT to lead to a reduction in pain.

Therefore, in this study we also investigated the role of actual physical activity in the reduction of pain during CBT for CFS.

\section{MATERIALS AND METHODS}

\section{Patients}

The original sample was comprised of patients with CFS. As not all CFS patients have pain and those who have no pain cannot show a decrease in pain after CBT, the criterion for inclusion into the present data analysis was that a patient had pain at the start of therapy. Patients were only included in the current study when they answered "yes" to the question "Do you have pain complaints?". The other inclusion criteria were the same as Heins et al, ${ }^{17}$ namely meeting $\mathrm{CDC}$-criteria for $\mathrm{CFS}^{2,3}$ - being severely fatigued operationalized as scoring Z35 on the subscale fatigue severity of the Checklist Individual Strength (CIS) ${ }^{13,24}$ this is 2 SDs above the mean of a healthy reference group, ${ }^{13}$ being severely disabled operationalized as scoring Z700 on the Sickness Impact Profile 8 (SIP8), ${ }^{25-27}$ being aged between 18 and 65 years, being able to read and write Dutch. Patients were excluded if they were currently applying for a disability claim, therapy was postponed until their application was completed. Of the 183 patients Heins et $\mathrm{al}^{17}$ included, 142 (78\%) patients reported to have pain at the start of therapy.

The study was conducted according to the Helsinki declaration as revised in 1994, and approved by the local ethical committee. All participants gave written informed consent before participation.

\section{CBT Intervention}

CBT for CFS is aimed at a gradual increase of activity and challenging fatiguerelated dysfunctional beliefs. At the start of the therapy patients define concrete personal goals.

These goals usually include the resumption of work, hobbies, and other activities that imply recovery of CFS.

Recovery is defined as no longer being severely fatigued and no longer being disabled. First, to stop potential disruption of the circadian rhythm, patients are asked to regulate their bedtimes and stop sleeping during the day. Next, the therapist distinguishes and challenges nonaccepting and catastrophizing thoughts that inhibit adequate coping.

Also, patients learn how to divert their attention away from the fatigue. With respect to activity, 2 groups of patients are distinguished: relatively active patients, who are characterized by bursts of physical activity followed by periods of prolonged rest and low active patients, who have extremely low activity levels on most days. ${ }^{28}$

Relatively active patients first learn how to spread their activities more evenly across the day. Low active patients start with a graded activity program immediately after the initial cognitive interventions.

This activity program consists of gradually increased daily walking or cycling. The increase in activity is time contingent, which means the increase in activity is not 
Bloot, L., Heins, M.J., Donders, R., Bleijenberg, G., Knoop, H. The process of change in pain during cognitive-behavior therapy for chronic fatigue syndrome. Clinical Journal of Pain: 2015, 31(10), 914-921

determined by the level of symptoms. When patients succeed in increasing their physical activity, they also begin to increase their social and mental activities. In the last phase of therapy, patients work systematically toward achieving their goals. When these goals are reached, patients are encouraged to perceive feelings of fatigue as a normal part of an active and healthy life and stop labelling themselves as a CFS patient. ${ }^{11,12}$

\section{MEASUREMENTS}

Measurements were planned pretherapy, at 6, 12, and 18 weeks after starting therapy, and posttherapy. The researcher provided the patients with the questionnaires and informed them that their answers would be treated as confidential; their therapist would not be informed about the process assessments. This information was also mentioned in the written information about the study and in the written instructions that were provided together with the questionnaires. Patients filled in the questionnaires at home.

\section{Pain Intensity}

Pain intensity was measured with a self-observation list, which patients filled out 4 times a day. ${ }^{4}$ Patients had to answer the question: "Did you experience pain in the last few hours?" and fill in a score ranging from 0 to 4 , with higher scores indicating higher pain intensity. Daily pain scores could range from 0 to 16. Pain intensity was measured during 12 days pretherapy and posttherapy. Pain intensity was also assessed for 4 complete days in the 3 interim assessments. We used the mean pain intensity score over 12 days for the premeasurements and postmeasurements and the mean score over 4 days for the interim measurements. Pain intensity was the primary outcome measure.

\section{Limitations Due to Pain}

Limitations due to pain were measured with the subscale pain of the Dutch version of the Medical Outcomes Survey SF-36. ${ }^{29}$ Scores can range from 0 to 100 , with higher scores indicating fewer limitations and less severe pain. The Cronbach alpha of the subscale of the Dutch version is $0.88,{ }^{30} 0.57$ in our participant sample.

\section{Fatigue}

Fatigue was assessed with the subscale fatigue severity of the $\mathrm{CIS}^{13}$ measuring the level of fatigue in the previous 2 weeks with 8 items on a 7-point scale (range, 8 to 56). A score of 35 or higher (ie, 2 SDs above the mean of a healthy control group) indicates severe fatigue. The Cronbach alpha ranges from 0.83 to 0.92 (Vercoulen et al, 1998; Vercoulen et al, 1994), ${ }^{31} 0.72$ in our sample.

\section{PROCESS VARIABLESSENSE OF CONTROL OVER FATIGUE}

The Self-Efficacy Scale was used to measure the sense of control over fatigue. ${ }^{32,33}$ The Self-Efficacy Scale comprises 5 items: Do you think you can influence your fatigue?; No matter what I do, I can't change my fatigue; Because of my attitude I can handle my fatigue; I think I could positively influence my fatigue; I feel powerless against my fatigue. Items are scored on a 5-point Likert scale that ranges from "No, I am convinced that is not true" to "Yes, I am convinced that is true." The total score ranges from 5 to 25 . Higher scores indicate a higher sense of control over fatigue. The internal consistency of this scale ranged between 0.68 and $0.77,,^{32,33} 0.74$ in our participant sample. 
Bloot, L., Heins, M.J., Donders, R., Bleijenberg, G., Knoop, H. The process of change in pain during cognitive-behavior therapy for chronic fatigue syndrome. Clinical Journal of Pain: 2015, 31(10), 914-921

\section{Focusing on Symptoms}

The subscale "focusing on symptoms" of the Illness Management Questionnaire was used to assess focusing on pain. ${ }^{34}$ This questionnaire assesses the patient's approach to symptoms in the last 6 months. Items are scored on a 6-point Likert-scale ranging from "never" to "always." The subscale "focusing on symptoms" consists of 9 items, with a Cronbach alpha of 0.88 indicating good reliability in CFS patients, ${ }^{34} 0.74$ in our participant sample.

\section{Actual Physical Activity}

To measure the actual physical activity an actometer was used. An actometer is a device that senses motion and is worn around the ankle. ${ }^{28}$ Every 5 minutes the mean number of accelerations is calculated. With these data a mean daily activity score can be calculated over the days that the device is worn. In this study activity was measured during 12 days before and after treatment. During treatment, physical activity was assessed during 4 complete days.

To ensure the device worked properly and to check compliance, data were checked visually. Days on which the actometer was worn for $<22$ hours were excluded from data analysis.

\section{Perceived Physical Activity}

An adapted version of the subscale Physical activity of the CIS was used to assess perceived physical activity. ${ }^{13,31}$ It consists of 3 items (I am physically very active; I am physically not very active; My level of physical activity is low) and measures the perceived level of physical activity in the previous 2 weeks. Items are scored on a 7point Likertscale. Higher scores indicate a lower level of physical activity. The Cronbach alpha in our sample was 0.80 .

\section{Physical Functioning}

The subscale Physical functioning of the Medical.

Outcomes Survey SF-36 was used to assess limitations in physical functioning. ${ }^{29}$ The subscale consists of 10 items, with a Cronbach alpha of 0.92 on the Dutch version indicating good reliability, ${ }^{30} 0.86$ in our participant sample.

Scores range from 0 to 100 , with higher scores indicating better physical functioning.

\section{Statistical Analyses}

Heins et $\mathrm{al}^{17}$ found a large variation in the response to therapy. They identified 4 response groups: fast responders (no longer severely fatigued within 6wk after start of therapy), midterm responders (no longer severely fatigued within 7 to $12 \mathrm{wk}$ after start of therapy), slow responders (no longer severely fatigued between $13 \mathrm{wk}$ after start of therapy and end of treatment), and nonresponders. To get an impression whether the change in fatigue and pain corresponds, we visualized the pattern of change in pain based on the response groups. First we depicted the mean change in pain intensity during therapy in the response groups as described by Heins and colleagues. A paired-samples t test was used to determine whether pain decreased significantly after therapy. To determine the size of change in pain during CBT an uncontrolled Cohen's d was calculated by dividing the mean difference in pain intensity during therapy by the pooled SD.

To determine the direction of change between fatigue and pain intensity a crosslagged analysis was performed. 
Bloot, L., Heins, M.J., Donders, R., Bleijenberg, G., Knoop, H. The process of change in pain during cognitive-behavior therapy for chronic fatigue syndrome. Clinical Journal of Pain: 2015, 31(10), 914-921

This cross-lagged analysis tested how pain intensity and fatigue at the different measurements were related, for example, whether pain intensity predicted fatigue at the following measurement. To estimate unknown regression parameters the likelihood method of estimation was used.

Missing values were imputed in Amos using multiple imputation with 20 replications. To assess model fit 3 goodness-of-fit indices were used: $\mathbf{W}_{2}$ test, Bentler comparative fit index (CFI), ${ }^{35}$ and the root mean square error of approximation value (RMSEA). ${ }^{36}$ Data were considered to fit the model when $\mathrm{W}_{2}$ statistics were nonsignificant $(P>0.05)$, RMSEA was smaller than 0.10 and CFI was above $0.95 .^{36,37}$ To test statistically whether changes in pain were related to changes in process variables, multiple regression analyses were performed. For each period independent variables were either values of process variables at the start of the period or changes in that variable during the same period, while controlling for fatigue at the start of the period. The change in observed pain during that period was used as dependent variable. Besides actual change scores we also performed the latter regression analyses with residualized change scores. Missing values were imputed with SPSS using multiple imputation with 20 replications.

Pooled results are reported.

SPSS AMOS 20.0 for Windows was used to perform the cross-lag analysis, SPSS 21.0 for Windows was used for data analysis. A $P$-value $<0.05$ was considered statistically significant.

\section{[TABLE 1]}

\section{RESULTS}

\section{Patients}

Of the 183 patients Heins et $\mathrm{al}^{17}$ included, 142 (78\%) patients reported to have pain at the start of therapy. Only patients who indicated that they had pain were included in the data analyses.

Mean age of these participants was 38.2 years, $80 \%$ were relatively active, and $78 \%$ were females. For mean scores on the questionnaires see Table 1.

\section{Treatment Outcome}

Pain intensity decreased significantly during therapy $\left(\mathrm{M}\right.$ difference $=\_1.95 ; 95 \%$ confidence interval [CI, 2.48 to _1.43]), $\left.\mathrm{t}_{126}=7.37, \mathrm{P}=0.001\right)$. As there was no control group in this study, we calculated the uncontrolled (within treatment group) Cohen's d. The uncontrolled Cohen's d was 0.67 (95\% CI, 0.18-1.19), which indicates a moderate effect size. Also, limitations caused by pain decreased significantly during therapy $\left(\mathrm{M}\right.$ difference $=\_17.46, \mathrm{t}_{140}=8.23, \mathrm{P}=0.001,95 \% \mathrm{CI}$, _21.66 to _13.27; the uncontrolled Cohen's $\overline{\mathrm{d}}$ was_0.79 (95\% CI, _4.4 to 3.1), which indicates a moderate effect size.

\section{Course of Change in Pain}

Thirty-three participants in the study were classified as fast responders with respect to their reduction in fatigue, 30 as midterm responders, 35 as slow responders, and 40 as nonresponders. Figure 1 shows that the patterns for the decrease in pain and fatigue were similar. 
Bloot, L., Heins, M.J., Donders, R., Bleijenberg, G., Knoop, H. The process of change in pain during cognitive-behavior therapy for chronic fatigue syndrome. Clinical Journal of Pain: 2015, 31(10), 914-921

The cross-lagged analysis indicated that a good model fit could not be obtained for pain intensity $\left(\mathrm{W}_{2} 486.4, \mathrm{df}=12, \mathrm{P}=0.001 ; \mathrm{CFI}=0.964, \mathrm{RMSEA}=0.118\right)$. This indicated that a direction of change could not be determined for pain intensity and fatigue.

\section{PROCESS VARIABLES RELATED TO CHANGE IN OBSERVED PAIN}

Regression analyses in which pain at the different measurements was predicted by process variables at the previous measurement (Table 2) showed that higher levels of physical functioning predicted lower levels of pain at the first interim measurement. Regression analyses in which changes in process variables predicted levels of pain (Table 3), while controlling for pain at the start of the period, showed that lower levels of pain are related to a decrease in focusing on symptoms. In the second and third period lower levels of pain were related to an increase in physical functioning. Changes in these process variables explained $14 \%$ of the change in fatigue in the first period, $4 \%$ in the second, and $7 \%$ in the third period.

\section{DISCUSSION}

CBT for CFS has a positive effect on both pain and fatigue. This study showed that a direction in change between fatigue and pain could not be established. The visual representation of the decrease in pain and fatigue suggests that both change simultaneously. The cognitivebehavioral variables that bring on reduction in fatigue in CBT for CFS were also partly responsible for the change in pain: an increase in self-reported physical functioning and a decrease in focusing on symptoms were related to lower levels of pain. The relationship found between the decrease in focusing on symptoms early in treatment and an increase in physical functioning later on in treatment and lower levels of pain, fit within the therapy protocol used. According to this protocol CFS patients first learn to distract their attention away from their symptoms, later on in therapy increasing physical functioning by graded activity is a central element. ${ }^{11,38}$ Actual changes in physical activity, self-efficacy, and perceived activity did not contribute significantly to lower levels of pain. A simultaneous change of pain and fatigue during CBT for CFS could be seen as an indication that the same processes are involved in the change in both pain and fatigue. We did find that the decrease in focusing on symptoms and increased physical functioning are related to both the reduction of fatigue and pain. It could be that the relationship between the reduction of fatigue and pain brought on by cognitive-behavioral interventions is unique for CFS, but we think it is likely that this relationship also exists in other conditions characterized by chronic pain. Fatigue is often mentioned as a debilitating symptom by patients with chronic pain. ${ }^{39}$ One could assume that behavioral interventions aimed at chronic pain also have a positive effect on fatigue. Another implication could be that behavioral interventions aimed at fatigue in populations with chronic pain might have a positive effect on pain and its consequences. Both possible implications of the current findings could be tested empirically.

In this study there were a limited number of time points, which made it more difficult to determine the direction of change between pain and fatigue. For future research we recommend including more time points in a closer time range to determine the direction of change in a cross-lagged analysis. 
Bloot, L., Heins, M.J., Donders, R., Bleijenberg, G., Knoop, H. The process of change in pain during cognitive-behavior therapy for chronic fatigue syndrome. Clinical Journal of Pain: 2015, 31(10), 914-921

\section{[FIGURE 1][TABLE 2][TABLE 3]}

We hypothesized that both an increase in actual physical activity and physical functioning would be related to a decrease in pain. Higher levels of actual physical activity were not related to lower levels of pain, but improvement in the level of physical functioning was. This is consistent with earlier findings with respect to the effect of CBT on fatigue, which showed that an increased physical functioning was related to a reduction in fatigue and actual physical activity is not. ${ }^{16,17,40}$ These 2 variables assess different aspects of physical activity. Actigraphy is used to assess the actual amount of physical activity. With the subscale physical functioning, a selfreport questionnaire, the patients' ability to perform specific physical activities is assessed. The latter consists of different kinds of activities, for example lifting, which also differ in intensity. Furthermore, patients only have to indicate if they are limited in carrying out these activities, which is quite different from the assessment of the amount of actual physical activity. Our results suggest that the reduction in limitations in specific physical activities is more closely related to pain than the increase of activity.

During CBT patients are encouraged to increase their physical activity temporarily, and are stimulated to change their cognitions about physical activity all through therapy.

Previous research has shown that CFS patients temporarily increase their actual physical activity and it was hypothesized that this temporary increase could work as a catalyst for changes in cognitions. ${ }^{17}$ In this study patients were selected based on a single question, namely whether patients had pain or not. Patients only had to report pain to be included, pain severity or impact of pain was not a selection criterion. This might be considered a limitation of this study.

Pain is a multidimensional concept that can be measured in various ways. The goal in this study was to measure pain intensity, for which a daily observed pain score (DOP) was used. This pain diary was filled in 4 times a day and averaged over the amount of days the diary was used. The DOP has been used before and has shown to be sensitive to detect change brought on by CBT. ${ }^{4}$ In addition, the SF-36 bodily pain score was used. The SF-36 is a widely used measure, but a limitation of the SF-36 is that it not only assesses pain severity but also limitations due to pain.

When using more generic assessments tools like the SF-36 physical functioning subscales it is difficult to differentiate between the impact of pain and the impact of other symptoms of CFS. The SF-36 bodily pain score asks respondents about their pain over a substantial longer time than the DOP. The former type of assessment can be more easily influenced by situational circumstances and memory biases than a pain diary. Our main outcome measure, the DOP also has limitations. For example, in our study it was not possible to control whether respondents filled in the scores at the requested time point. Instead of using penciland- paper questionnaires, one could use smartphones or PDA's that reminds the respondent of filling in their score and by doing so reducing the risk of forgetting to fill in a score to a minimum. ${ }^{41} \mathrm{We}$ assumed that changes in certain cognitive processes are responsible for both the reduction in fatigue and pain and suggested that these cognitive processes are associated with central sensitization. ${ }^{16,17}$ Although the cognitive processes in our treatment model show considerable overlap with the psychological factors associated with central sensitization, we did not directly measure this concept. However, the finding that a 
Bloot, L., Heins, M.J., Donders, R., Bleijenberg, G., Knoop, H. The process of change in pain during cognitive-behavior therapy for chronic fatigue syndrome. Clinical Journal of Pain: 2015, 31(10), 914-921

decreased focusing on symptom leads to a decrease in both pain and fatigue is in our view in accordance with the idea that the mechanism of central sensitization is underlying the increased perception of both pain and fatigue in CFS. It must also be concluded that the model tested for change in pain in this study explained substantially less than the model for fatigue, where $20 \%$ to $46 \%$ of the change in fatigue was explained. ${ }^{17}$ This could mean that the mechanisms of change in fatigue and pain only partly overlap. Possible other candidates for explaining the reduction in pain during CBT for CFS might be found in cognitive-behavioral models of chronic pain. In the fear-avoidance model of pain, catastrophizing of pain plays an important role. ${ }^{42}$ Another variable that could contribute to reducing pain in CFS is a reduction of kinesiophobia brought on by $\mathrm{CBT}^{43}$ Both pain catastrophizing and kinesiophobia are possible candidates for future research into process variables that are related to the reduction of pain in CFS. It could be that both candidates are related to the reduction in pain but not to a reduction in fatigue, suggesting that also other mechanisms than central sensitization to both pain and fatigue play a role. A limitation of this study is that the process variables we found do not predict changes in pain. We do not know whether changes in process variables lead to a decrease in pain, or vice versa. One could imagine that if pain reduces, focussing on symptoms decreases and physical functioning improves. For fatigue, it is suggested that instead of a cause-effect relationship, a complex reciprocal feedback process would be in order. ${ }^{17}$ When applied to the change in pain, a change in cognitions would lead to a reduction in pain, which would lead to a further change in cognitions, and so forth.

Another limitation of this study is that it only focused on changes in pain intensity. We do not know if the same variables mediate the reduction in impact of pain, as assessed with the SF-36. It would be interesting to determine what mediates the reduction in limitations due to pain.

The study of Knoop et $\mathrm{al}^{4}$ already showed that pain is a common symptom in CFS and that pain can be decreased by CBT. On the basis of this finding, an intervention for pain was added to CBT for CFS. This intervention, which is used later on in therapy, focuses on decreasing of catastrophizing beliefs about pain. Perhaps if this intervention is used earlier in therapy and more consistently throughout CBT more reduction of pain can be achieved. It is also important to inform patients at the start of CBT that the pain is likely to decrease when the fatigue decreases. Increasing outcome expectations in this way could possibly improve the outcome of CBT for CFS with respect to pain. ${ }^{44}$ Previous research has shown that more positive outcome expectations are related to a larger decrease in fatigue in CFS patients. Perhaps the same is true for pain in CFS.

In conclusion, the results of this study suggest that pain and fatigue decrease simultaneously during CBT for CFS. Changes in physical functioning and symptom focus play an important role in the reduction of pain in CFS. As with fatigue, actual physical activity does not lead to a reduction in pain, suggesting that in CBT physical activity is not directly related to a reduction in symptoms. In the reduction of fatigue and pain different processes seem to play a role, but in both fatigue and pain an increased physical functioning and a reduced focusing on symptoms are related to a decrease of symptoms. Especially the latter finding is in accordance with an assumed underlying central mechanism of sensitization in pain and fatigue in CFS, which may imply a more general impairment in the perception of bodily signals in CFS. 
Bloot, L., Heins, M.J., Donders, R., Bleijenberg, G., Knoop, H. The process of change in pain during cognitive-behavior therapy for chronic fatigue syndrome. Clinical Journal of Pain: 2015, 31(10), 914-921

\section{REFERENCES}

1. Prins JB, van der Meer JW, Bleijenberg G. Chronic fatigue syndrome. Lancet. 2006;367:346-355.

2. Fukuda K, Straus SE, Hickie I, et al. The chronic fatigue syndrome: a comprehensive approach to its definition and study. International Chronic Fatigue Syndrome Study Group. Ann Intern Med. 1994;121:953-959.

3. Reeves WC, Lloyd A, Vernon SD, et al. International Chronic Fatigue Syndrome Study G. Identification of ambiguities in the 1994 chronic fatigue syndrome research case definition and recommendations for resolution. BMC Health Serv Res. 2003;3:25.

4. Knoop H, Stulemeijer M, Prins JB, et al. Is cognitive behaviour therapy for chronic fatigue syndrome also effective for pain symptoms?. Behav Res Ther. 2007;45:2034-2043.

5. King C, Jason LA. Improving the diagnostic criteria and procedures for chronic fatigue syndrome. Biol Psychol. 2005;68:87-106.

6. Meeus M, Nijs J, Meirleir KD. Chronic musculoskeletal pain in patients with the chronic fatigue syndrome: a systematic review. Eur J Pain. 2007;11:377-386.

7. Meeus M, Nijs J, Van Mol E, et al. Role of psychological aspects in both chronic pain and in daily functioning in chronic fatigue syndrome: a prospective longitudinal study. Clin Rheumatol. 2012;31:921-929.

8. Castell BD, Kazantzis N, Moss-Morris RE. Cognitive behavioral therapy and graded exercise for chronic fatigue syndrome: a meta-analysis. Clin Psychol Sci Pract. 2011; 18:311-324.

9. White PD, Goldsmith KA, Johnson AL, et al. Group Ptm. Comparison of adaptive pacing therapy, cognitive behaviour therapy, graded exercise therapy, and specialist medical care for chronic fatigue syndrome (PACE): a randomised trial. Lancet. 2011;377:823-836.

10. Price JR, Mitchell E, Tidy E, et al. Cognitive behaviour therapy for chronic fatigue syndrome in adults. The Cochrane database of systematic reviews. 2008;CD001027.

11. Knoop HBG. Chronic fatigue syndrome: a cognitive behavioral treatment protocol for CFS. Houten: Bohn, Stafleu en van Loghum; 2010.

12. Bleijenberg G, Prins JB, Bazelmans E. Cognitive behavioural therapies. In: Jason LA, Fennell PA, Taylor RR, eds.

Handbook of Chronic Fatigue Syndrome. New York, NY: Wiley \& Sons; 2003.

13. Vercoulen JH, Bazelmans E, Swanink CM, et al. Physical activity in chronic fatigue syndrome: assessment and its role in fatigue. J Psychiatr Res. 1997;31:661-673.

14. Vercoulen JH, Swanink CM, Galama JM, Fennis JF, Jongen PJ, Hommes OR, et al. The persistence of fatigue in chronic fatigue syndrome and multiple sclerosis: development of amodel. J Psychosom Res. 1998;45:507-517.

15. Frazier PA, Tix AP, Barron KE. Testing moderator and mediator effects in counseling psychology research. J Couns Psychol. 2004;51:115-134.

16. Wiborg JF, Knoop H, Frank LE, et al. Towards an evidencebased treatment model for cognitive behavioral interventions focusing on chronic fatigue syndrome. J Psychosom Res. 2012;72:399-404.

17. Heins M, Knoop H, Burke W, et al. The process of cognitive behaviour therapy for chronic fatigue syndrome: which changes in perpetuating cognitions and behaviour are related to a reduction in fatigue?. J Psychosom Res. 2013;75:235-241.

18. Nijs J, Crombez G, Meeus M, et al. Pain in patients with chronic fatigue syndrome: time for specific pain treatment?. Pain Physician. 2012;15:E677-E686.

19. Ellingson LD, Shields MR, Stegner AJ, et al. Physical activity, sustained sedentary behavior, and pain modulation in women with fibromyalgia. J Pain. 2012;13:195-206.

20. Kashikar-Zuck S, Flowers SR, Verkamp E, et al. Actigraphybased physical activity monitoring in adolescents with juvenile primary fibromyalgia syndrome. J Pain. 2010;11:885-893.

21. Mannion AF, Taimela S, Muntener M, et al. Active therapy for chronic low back pain part 1. Effects on back muscle activation, fatigability, and strength. Spine. 2001;26:897-908.

22. Koltyn KF, Arbogast RW. Perception of pain after resistance exercise. Br J Sports Med. 1998;32:20-24.

23. Ray CA, Carter JR. Central modulation of exercise-induced muscle pain in humans. J Physiol. 2007;585:287-294. 
Bloot, L., Heins, M.J., Donders, R., Bleijenberg, G., Knoop, H. The process of change in pain during cognitive-behavior therapy for chronic fatigue syndrome. Clinical Journal of Pain: 2015, 31(10), 914-921

24. Bultmann U, de Vries M, Beurskens AJ, et al. Measurement of prolonged fatigue in the working population: determination of a cutoff point for the checklist individual strength. $J$ Occup Health Psychol. 2000;5:411-416.

25. Knoop H, Bleijenberg G, Gielissen MF, et al. Is a full recovery possible after cognitive behavioural therapy for chronic fatigue syndrome?. Psychother Psychosom. 2007;76:171176.

26. Pollard WE, Bobbitt RA, Bergner M, et al. The Sickness Impact Profile: reliability of a health status measure. Med Care. 1976;14:146-155.

27. Bergner M, Bobbitt RA, Pollard WE, et al. The Sickness Impact Profile: validation of a health status measure. Med Care. 1976;14:57-67.

28. van der Werf SP, Prins JB, Vercoulen JH, et al. Identifying physical activity patterns in chronic fatigue syndrome using actigraphic assessment. J Psychosom Res. 2000;49:373379.

29. Stewart AL, Hays RD, Ware JE Jr. The MOS short-form general health survey. Reliability and validity in a patient population. Med Care. 1988;26:724-735.

30. van der Zee K, Sanderman R. Measuring Overall Health Status With the MOS SF36: A Manual. Groningen: Noordelijk Centrum voor Gezondheidsvraagstukken; 1993.

31. Vercoulen JH, Swanink CM, Fennis JF, Galama JM, van der Meer JW, Bleijenberg G.. Dimensional assessment of chronic fatigue syndrome. J Psychosom Res. 1994;38:383392.

32. De Vree B, Van der Werf S, Prins JB, et al. Measurement instruments in chronic fatigue. Gedragstherapie. 2002;35:157-164.

33. Prins JB, Bleijenberg G, Bazelmans E, et al. Cognitive behaviour therapy for chronic fatigue syndrome: a multicentre randomised controlled trial. Lancet. 2001;357:841-847.

34. Ray C, Weir W, Stewart D, et al. Ways of coping with chronic fatigue syndrome: development of an illness management questionnaire. Soc Sci Med. 1993;37:385-391.

35. Bentler PM. Comparative fit indexes in structural models. Psychol Bull. 1990;107:238246.

36. Browne MW, Cudeck R. Alternative ways of assessing model fit. In: Bollen KA, Long JS, eds. Testing Structural Equation Models. Newbury Park, CA: Sage publications; 1993.

37. Bollen KA. Overall fit in covariance structure models: two types of sample size effects. Psychol Bull. 1990;107:256-259.

38. Knoop H, Prins JB, Moss-Morris R, et al. The central role of cognitive processes in the perpetuation of chronic fatigue syndrome. J Psychosom Res. 2010;68:489-494.

39. Creavin ST, Dunn KM, Mallen CD, et al. Co-occurrence and associations of pain and fatigue in a community sample of Dutch adults. Eur J Pain. 2010;14:327-334.

40. Wiborg JF, Knoop H, Stulemeijer M, et al. How does cognitive behaviour therapy reduce fatigue in patients with chronic fatigue syndrome? The role of physical activity. Psychol Med. 2010;40:1281-1287.

41. Sorbi MJ, Mak SB, Houtveen JH, et al. Mobile web-based monitoring and coaching: feasibility in chronic migraine. J Med Internet Res. 2007;9:e38.

42. Vlaeyen JW, Linton SJ. Fear-avoidance and its consequences in chronic musculoskeletal pain: a state of the art. Pain. 2000;85:317-332.

43. Nijs J, Vanherberghen K, Duquet W, et al. Chronic fatigue syndrome: lack of association between pain-related fear of movement and exercise capacity and disability. Phys Ther. 2004;84:696-705.

44. Heins MJ, Knoop H, Bleijenberg G. The role of the therapeutic relationship in cognitive behaviour therapy for chronic fatigue syndrome. Behav Res Ther. 2013;51:368-376. 
Bloot, L., Heins, M.J., Donders, R., Bleijenberg, G., Knoop, H. The process of change in pain during cognitive-behavior therapy for chronic fatigue syndrome. Clinical Journal of Pain: 2015, 31(10), 914-921

\section{TABLES AND FIGURES}

TABLE 1. Mean Scores and SDs Pretherapy and Posttherapy on the Questionnaires of the Included Patients

\begin{tabular}{lrrrrr}
\hline & Pre & & & Post & \\
\cline { 2 - 3 } & $\boldsymbol{M}$ & SD & & \multicolumn{1}{c}{$\boldsymbol{M}$} & SD \\
\hline SF-36 Pain & 50.7 & 21.3 & & 68.0 & 22.6 \\
Daily observed pain severity & 6.1 & 3.0 & & 4.0 & 3.0 \\
\hline
\end{tabular}

FIGURE 1. A, Decrease in fatigue during treatment for each response group. B, Decrease in pain during treatment for each response group.

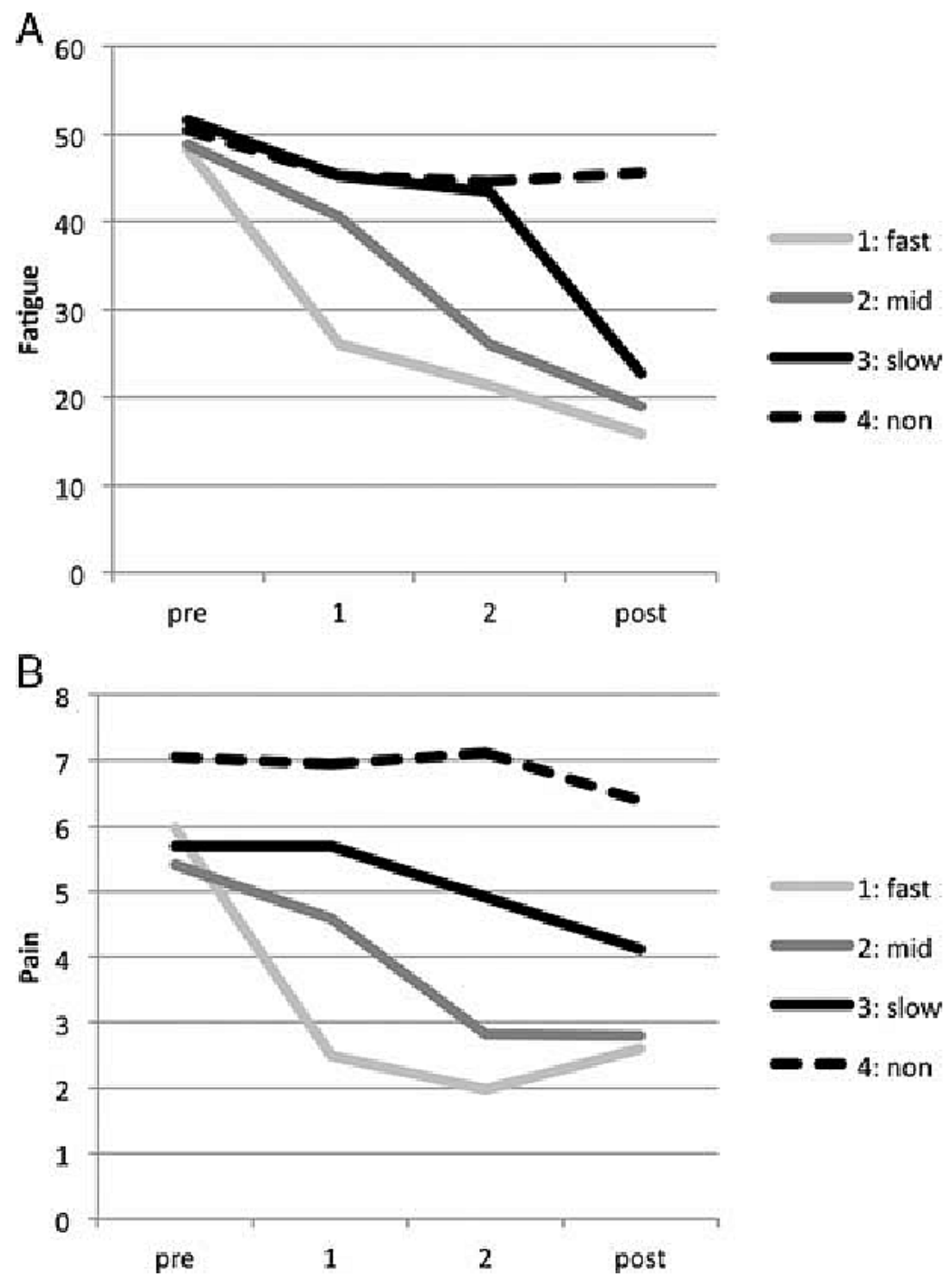


Bloot, L., Heins, M.J., Donders, R., Bleijenberg, G., Knoop, H. The process of change in pain during cognitive-behavior therapy for chronic fatigue syndrome. Clinical Journal of Pain: 2015, 31(10), 914-921

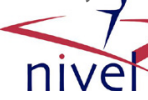

TABLE 2. Multiple Regression Models of Levels of Pain Predicted by Process Variables at the Previous Measurement $(n=142)$

\begin{tabular}{|c|c|c|c|c|c|c|c|c|c|c|c|c|}
\hline & \multicolumn{4}{|c|}{ Pain Interim 1} & \multicolumn{4}{|c|}{ Pain Interim 2} & \multicolumn{4}{|c|}{ Pain Post } \\
\hline & $B$ & SE & $t$ & $P$ & $B$ & SE & $t$ & $P$ & $B$ & SE & $t$ & $P$ \\
\hline Pain prev & 0.463 & 0.083 & 5.603 & 0.000 & 0.744 & 0.076 & 9.850 & 0.000 & 0.679 & 0.074 & 9.144 & 0.000 \\
\hline Perceived activity prev & -0.122 & 0.065 & -1.885 & 0.059 & 0.042 & 0.055 & 0.760 & 0.447 & 0.066 & 0.050 & 1.324 & 0.185 \\
\hline Focus prev & -0.024 & 0.028 & -0.849 & 0.396 & -0.019 & 0.030 & -0.649 & 0.516 & -0.003 & 0.028 & -0.098 & 0.922 \\
\hline Sense of control prev & -0.085 & 0.079 & -1.070 & 0.285 & -0.088 & 0.090 & -0.980 & 0.327 & -0.042 & 0.066 & -0.634 & 0.526 \\
\hline Physical funct. prev & -0.042 & 0.013 & -3.272 & 0.001 & -0.013 & 0.013 & -1.018 & 0.309 & 0.000 & 0.013 & -0.019 & 0.985 \\
\hline Objective activity prev & 0.015 & 0.014 & 1.093 & 0.275 & 0.002 & 0.011 & 0.227 & 0.821 & -0.007 & 0.008 & -0.876 & 0.381 \\
\hline
\end{tabular}

$R^{2}$ is $0.27,0.59$, and 0.58 , respectively. Estimates are unstandardized and reflect predicted pain when the predictor (process variable at previous measurement) increases 1 point.

Focus indicates subscale focusing Illness Management Questionnaire; Objective activity, mean daily activity score as measured with the actigraph; Pain, daily observed pain; Perceived act, subscale perceived activity of the Checklist Individual Strength; Physical funct., subscale physical functioning of the SF-36; prev, value at previous measurement; Sense of control, Self-Efficacy Scale.

TABLE 3. Multiple Regression Models of Levels of Pain Predicted by Changes in Process Variables During the Same Period $(n=142)$

\begin{tabular}{|c|c|c|c|c|c|c|c|c|c|c|c|c|}
\hline & \multicolumn{4}{|c|}{ Pain Interim 1} & \multicolumn{4}{|c|}{ Pain Interim 2} & \multicolumn{4}{|c|}{ Pain Post } \\
\hline & $B$ & SE & $t$ & $P$ & $B$ & SE & $t$ & $P$ & $B$ & SE & $t$ & $\boldsymbol{P}$ \\
\hline Pain prev & 0.566 & 0.078 & 7.224 & 0.000 & 0.772 & 0.065 & 11.915 & 0.000 & 0.744 & 0.069 & 10.737 & 0.000 \\
\hline$\Delta$ Perceived activity & 0.016 & 0.056 & 0.292 & 0.770 & 0.034 & 0.053 & 0.647 & 0.518 & 0.021 & 0.041 & 0.521 & 0.602 \\
\hline$\Delta$ Focus & 0.076 & 0.032 & 2.390 & 0.017 & 0.053 & 0.032 & 1.666 & 0.096 & 0.004 & 0.026 & 0.162 & 0.871 \\
\hline$\Delta$ Sense of control & -0.090 & 0.078 & -1.155 & 0.248 & 0.027 & 0.092 & 0.290 & 0.772 & -0.071 & 0.062 & -1.142 & 0.254 \\
\hline$\Delta$ Physical funct. & -0.027 & 0.014 & -1.859 & 0.063 & -0.034 & 0.016 & -2.072 & 0.038 & -0.034 & 0.014 & -2.378 & 0.018 \\
\hline$\Delta$ Objective activity & -0.002 & 0.010 & -0.188 & 0.851 & -0.003 & 0.009 & -0.348 & 0.729 & -0.006 & 0.008 & -0.712 & 0.477 \\
\hline
\end{tabular}

Adjusted $R^{2}$ is $0.32,0.64$, and 0.62 and $r^{2}$ change $0.14,0.04$, and 0.07 , respectively. Estimates are unstandardized and reflect change in fatigue when the predictor (process variable at the start of period or change in process variable during the period) increases 1 point.

$\Delta$ indicates change since previous measurement; Focus, subscale focusing Illness Management Questionnaire; Objective activity, mean daily activity score as measured with the actometer; Prev, value at previous measurement; Pain, daily observed pain; Perceived act, subscale perceived activity of the Checklist Individual Strength; Physical funct., subscale physical functioning of the SF-36; Sense of control, Self-Efficacy Scale. 